\title{
Nitrogen Fixation at Early Mars
}

\author{
Danica Adams, ${ }^{1, i}$ Yangcheng Luo, ${ }^{1}$ Michael L. Wong, ${ }^{2,3}$ Patrick Dunn, ${ }^{4}$ \\ Madeline Christensen, ${ }^{1,5}$ Chuanfei Dong, ${ }^{6, i i}$ Renyu Hu, ${ }^{1,7}$ and Yuk Yung ${ }^{1,7}$
}

\begin{abstract}
The Mars Science Laboratory (MSL) recently discovered nitrates in Gale Crater (e.g., Stern et al., 2015; Sutter et al., 2017). One possible mechanism for ancient nitrate deposition on Mars is through HNOx formation and rain out in the atmosphere, for which lightning-induced NO is likely the fundamental source. This study investigates nitrogen $\left(\mathrm{N}_{2}\right)$ fixation in early Mars' atmosphere, with implications for early Mars' habitability. We consider a 1 bar atmosphere of background $\mathrm{CO}_{2}$, with abundance of $\mathrm{N}_{2}$, hydrogen, and methane varied from $1 \%$ to $10 \%$ to explore a swath of potential early Mars climates. We derive lightning-induced thermochemical equilibrium fluxes of $\mathrm{NO}$ and $\mathrm{HCN}$ by coupling the lightning-rate parametrization from the study of Romps et al. (2014) with chemical equilibrium with applications, and we use a Geant4 simulation platform to estimate the effect of solar energetic particle events. These fluxes are used as input into KINETICS, the Caltech/JPL coupled photochemistry and transport code, which models the chemistry of 50 species linked by 495 reactions to derive rain-out fluxes of HNOx and $\mathrm{HCN}$. We compute equilibrium concentrations of cyanide and nitrate in a putative northern ocean at early Mars, assuming hydrothermal vent circulation and photoreduction act as the dominant loss mechanisms. We find average oceanic concentrations of $\sim 0.1-2 \mathrm{nM}$ nitrate and $\sim 0.01-2 \mathrm{mM}$ cyanide. $\mathrm{HCN}$ is critical for protein synthesis at concentrations $>0.01 \mathrm{M}$ (e.g., Holm and Neubeck, 2009), and our result is astrobiologically significant if secondary local concentration mechanisms occurred. Nitrates may act as highpotential electron acceptors for early metabolisms, although the minimum concentration required is unknown. Our study derives concentrations that will be useful for future laboratory studies to investigate the habitability at early Mars. The aqueous nitrate concentrations correspond to surface nitrate precipitates of $\sim 1-8 \times 10^{-4}$ wt $\%$ that may have formed after the evaporation of surface waters, and these values roughly agree with recent MSL measurements. Key Words: Nitrogen fixation-Early Mars-Astrobiology—Nitrate. Astrobiology 21, 968-980.
\end{abstract}

\section{Introduction}

T He Mars Science Laboratory (MSL) recently discovered 70-260 and 330-1100 ppm of nitrate in the Klein and Cumberland Noachian-aged mudstone deposits, respectively, at Yellowknife Bay (Stern et al., 2015). Subsequent measurements of $0.002-0.05 \mathrm{wt} \%$ of nitrate in sediments near Gale Crater were also reported (Sutter et al., 2017). One possible mechanism for nitrate deposition is through HNOx formation and rain out in the atmosphere, for which lightning-induced NO is the fundamental source (e.g., Schuman and Huntrieser, 2007; Ducluzeau et al., 2009). At early Mars, electrical discharges would have heated local air parcels to tens of thousands of Kelvin, encouraging the following chemical processes (e.g., Wong et al., 2017):

$$
\begin{gathered}
\mathrm{CO}_{2} \rightarrow \mathrm{CO}+\mathrm{O} \\
\mathrm{O}+\mathrm{N}_{2} \rightarrow \mathrm{NO}+\mathrm{N} \\
\mathrm{N}+\mathrm{CO}_{2} \rightarrow \mathrm{NO}+\mathrm{CO} .
\end{gathered}
$$

Photochemical pathways then produce HNOx from NO and oxidizing species, followed by subsequent rain out into

\footnotetext{
${ }^{1}$ Department of Geological and Planetary Sciences, California Institute of Technology, Pasadena, California, USA.

${ }^{2}$ Department of Astronomy and Astrobiology Program, University of Washington, Seattle, Washington, USA.

${ }^{3}$ Virtual Planet Laboratory, University of Washington, Seattle, Washington, USA.

${ }^{4}$ Space Sciences Laboratory, University of California, Berkeley, Berkeley, California, USA.

${ }^{5}$ Bellarmine Preparatory, Tacoma, Washington, USA.

${ }^{6}$ Department of Astrophysical Sciences, Princeton University, Princeton, California, USA.

${ }^{7}$ Jet Propulsion Laboratory, California Institute of Technology, Pasadena, California, USA.

${ }^{\mathrm{i}}$ ORCID ID (https://orcid.org/0000-0001-9897-9680).

ii ORCID ID (https://orcid.org/0000-0002-8990-094X).
} 
a depositional environment. Wong et al. (2017) investigated the production and precipitation of HNOx through this pathway in early Earth environments. This mechanism is likely applicable to early Mars, as extensive geological and mineralogical evidence at the present surface suggests that liquid water once flowed and precipitated on the surface during the late Noachian (e.g., Baker et al., 2006; Bibring et al., 2006; Milliken et al., 2010; McEwen et al., 2013; Grotzinger et al., 2015).

$\mathrm{HCN}$ may be produced as a dissociation product of nitrogen $\left(\mathrm{N}_{2}\right)$ and methane $\left(\mathrm{CH}_{4}\right)$ (i.e., in the presence of lightning, as well as solar energetic particle [SEP] events). $\mathrm{HCN}$ is also soluble, and we expect it would have also precipitated to the early Mars surface during times of a warm wet climate. We thus also examine the surface flux of $\mathrm{HCN}$ rain out. Multiple pathways to produce $\mathrm{HCN}$ from radicals have been suggested (Pearce et al., 2019). The dominant formation mechanisms in this study are summarized in Fig. $7 \mathrm{~b}$, and the complete reaction table (with rate constants and column rates) is provided in Supplementary Appendix SA1.

The $\mathrm{N}_{2}$ cycle at early Mars remains a long-standing question of significant astrobiological relevance; specifically, lightning-induced production of $\mathrm{HCN}$ and nitrogen oxides may have been key to the onset of both early terrestrial and possibly martian life.

\subsection{Astrobiological implications of $\mathrm{HCN}$}

HCN production may have been relevant to synthesizing prebiotic molecules (e.g., Ritson and Sutherland 2012, 2013; Sutherland 2017). It has been hypothesized that prebiotic synthesis of adenine from HCN may have made adenine readily available in early terrestrial environments (e.g., Holm and Neubeck, 2009). The purine coding elements of RNA, adenine in particular, can be synthesized in an efficient process from HCN (Oro, 1960, 1961). Although this synthesis would have required high concentrations of $\mathrm{HCN}$ $(>0.01 \mathrm{M})$, strong absorption through zeolites (Fripiat et al., 1972) and other concentrating mechanisms has been suggested to allow for synthesis through compartmentalization in an otherwise more dilute solution of HCN (e.g., Holm and Neubeck, 2009). In this study, we investigate the HCN produced by lightning and photochemistry involving radicals produced from SEP events, but we acknowledge that formation could have also been encouraged by UV radiation and geothermal energy sources.

\subsection{Astrobiological implications of NOx}

It has been hypothesized that nitrogen oxides may have acted as high-potential electron acceptors for early metabolic processes (e.g., Mancinelli and McKay, 1988). Nitrate $\left(\mathrm{NO}_{3}^{-}\right)$and nitrite $\left(\mathrm{NO}_{2}^{-}\right)$could have provided the free energy gradient to drive the first metabolic pathway through oxidizing hydrothermal $\mathrm{CH}_{4}$ while hydrogenating $\mathrm{CO}_{2}$ at alkaline hydrothermal vents (e.g., Ducluzeau et al., 2009; Nitschke and Russell, 2013; Shibuya et al., 2016). For this mechanism to proceed, nitrogen oxides are required as highpotential electron acceptors. First, their presence would help set up the initial disequilibrium required to activate $\mathrm{CH}_{4}$, which is converted to methanol as nitrate and nitrite are rereduced to nitric oxide, NO (Nitschke and Russell, 2013).
Second, they could potentially facilitate electron bifurcation, in which the acceptance of an outer shell molybdenum electron would be coupled to the reduction of $\mathrm{CO}_{2}$ (the low-potential electron acceptor) to CO (SchoeppCothenet et al., 2012; Nitschke and Russell, 2013; Helz et al., 2014). The astrobiological relevance of lightninginduced $\mathrm{N}_{2}$ fixation in the early terrestrial atmosphere has been considered and was motivated by these mechanisms in the study of Wong et al. (2017).

\subsection{Relevance of the early Mars climate}

As already mentioned, its present-day surface morphology indicates that early Mars was likely warm and wet during the late Noachian, suggesting a drastically different early climate than the present. This climate is key to inferring the nature of the early Mars $\mathrm{N}_{2}$ cycle. Since this article seeks to examine $\mathrm{HCN}$ and HNOx production, it is critical to first understand the nature of the early atmosphere in which these molecules would have formed.

Despite the evidence for a warm wet early Mars, a zeroalbedo early Mars would have hosted an equilibrium temperature of only $210 \mathrm{~K}$, far from the phase transition for liquid water. With a semimajor axis of $1.524 \mathrm{AU}$, Mars only receives $\sim 43 \%$ of the solar flux received by Earth. The early Sun (at $3.8 \mathrm{Ga}$ ) contributed to this cool temperature as it was only $\sim 75 \%$ as luminous as the presentday Sun; the energy output of stellar cores increases with time as they contract due to the increasing mean molecular weight yielded from $\mathrm{H}_{2}$ fusion (Gough, 1981). Hence, this evidence for surface water is paradoxical and begs the question: what early Mars climate was capable of sufficiently warming the surface?

It has been hypothesized that early Mars likely hosted a much thicker atmosphere enriched with greenhouse gases. Kasting (1991) demonstrated that a $\mathrm{CO}_{2}-\mathrm{H}_{2} \mathrm{O}$ atmosphere (i.e., an atmosphere dominated by greenhouse gases) would have increased the planetary albedo through Rayleigh scattering and cloud condensation and would thus be insufficient to warm early Mars. Other surface warming processes have been investigated but yielded insufficient surface warming; these include but are not limited to cirrus clouds (e.g., Ramirez and Kasting, 2017), water clouds (e.g., Urata and Toon, 2013), $\mathrm{CO}_{2}$ clouds (e.g., Forget and Pierrehumbert, 1997), sulfur dioxide from volcanic outgassing (e.g., Halevy and Head, 2014), and orbital obliquity and eccentricity variations and/or diurnal variations (e.g., Wordsworth et al., 2013). Although the present Mars atmosphere is oxidizing due to efficient $\mathrm{H}_{2}$ escape, it has recently been suggested that the early atmosphere may have been more reducing. Collisionally induced absorption of $\mathrm{CO}_{2}$ with $\mathrm{CH}_{4}$ and $\mathrm{H}_{2}$, due to both induced dipole and dimer effects (Gruszka and Borysow, 1997; Baranov et al., 2004), could provide sufficient climate forcing to allow at least transient liquid water on the early martian surface (e.g., Ramirez and Kasting, 2014; Wordsworth et al., 2017). The climate model presented in the study of Wordsworth et al. (2017) produces global mean surface temperatures $>273 \mathrm{~K}$ with atmospheric pressures $<2$ bar. This atmospheric pressure is consistent with estimates of carbon isotope fractionation (Hu et al., 2015), an upper limit derived from surface crater distributions (Kite et al., 2014), and the 
estimated time-integrated atmospheric loss derived from the Mars Atmospheric and EvolutioN mission (Jakosky et al., 2018). We consider it likely that $\mathrm{H}_{2}$ and $\mathrm{CH}_{4}$ were important greenhouse gases on early Mars; however, their early abundances are still highly uncertain.

Throughout this study, we assume a background 1 bar $\mathrm{CO}_{2}$ atmosphere and vary the abundances of $\mathrm{N}_{2}, \mathrm{H}_{2}$, and $\mathrm{CH}_{4}$ from $1 \%$ to $10 \%$. The precise phase space is summarized in Table 1.

These mixing ratios of reduced gases are motivated, in part, by their contribution to the greenhouse effect, but also by geochemistry. Note that these geochemical sourcesserpentinization-induced $\mathrm{CH}_{4}$ fluxes of $\sim 10^{10}-10^{12} /\left(\mathrm{cm}^{2} \cdot \mathrm{s}\right)$ (Etiope et al., 2013; Wordsworth et al., 2017), in combination with release from methane clathrates, impact degassing, and volcanic outgassing — would have competed with atmospheric escape and photochemical destruction for $\mathrm{H}_{2}$ and $\mathrm{CH}_{4}$, respectively. Methane clathrates may have formed in the presence of surface ice and serpentine (Lasue et al., 2015). Theoretical equilibrium calculations of carbonaceous chondrite impactors suggest $\mathrm{CH}_{4}$ as the dominant C-bearing specie outgassed (Schaeger and Fegley, 2007). The interior of Mars may not have reached the temperature and pressure required to undergo the spinel-to-perovskite transition at $1900 \mathrm{~K}$ and $24 \mathrm{GPa}$ (Chudinovskikh and Boehler, 2001) that would make the interior more reduced; if Mars had a lower oxygen fugacity mantle, magmatic outgassing could have yielded a $\mathrm{CH}_{4}$-rich atmosphere (Wadhwa, 2001). Relatively low mixing ratios would have been likely, due to the competition of photochemistry with geochemical sources, and Wordsworth et al. (2017) found that mixing ratios $<10 \%$ are able to sufficiently warm early Mars to sustain transient surface liquid water. Wordsworth et al. (2017) noted that the mixed $\mathrm{CO}_{2}-\mathrm{CH}_{4}-\mathrm{H}_{2}$ composition would likely persist over

Table 1. Summary of the 40 Atmospheric Compositions We CONSIDER

\begin{tabular}{|c|c|c|c|c|c|}
\hline \multirow{2}{*}{$\mathbf{C H}_{\mathbf{4}}$} & \multicolumn{4}{|c|}{$\mathbf{N}_{\mathbf{2}}$} & \\
\hline \multirow{3}{*}{$1 \%$} & & $3 \%$ & $5 \%$ & $10 \%$ & $\mathbf{H}_{\mathbf{2}}$ \\
\hline & $\bigcirc$ & $\bigcirc$ & $\bigcirc$ & $\bigcirc$ & $1 \%$ \\
& $\bigcirc$ & $\bigcirc$ & $\bigcirc$ & $\bigcirc$ & $3 \%$ \\
\hline \multirow{3}{*}{$3 \%$} & $\bigcirc$ & $\bigcirc$ & $\bigcirc$ & $\bigcirc$ & $1 \%$ \\
& $\bigcirc$ & $\bigcirc$ & $\bigcirc$ & $\bigcirc$ & $3 \%$ \\
& $\bigcirc$ & $\bigcirc$ & $\bigcirc$ & $\bigcirc$ & $5 \%$ \\
\hline \multirow{3}{*}{$5 \%$} & $\bigcirc$ & $\bigcirc$ & $\bigcirc$ & $\bigcirc$ & $3 \%$ \\
& $\bigcirc$ & $\bigcirc$ & $\bigcirc$ & $\bigcirc$ & $5 \%$ \\
& $\bigcirc$ & $\bigcirc$ & $\bigcirc$ & $\bigcirc$ & $10 \%$ \\
\hline \multirow{3}{*}{$10 \%$} & $\bigcirc$ & $\bigcirc$ & $\bigcirc$ & $\bigcirc$ & $1 \%$ \\
& $\bigcirc$ & $\bigcirc$ & $\bigcirc$ & $\bigcirc$ & $3 \%$ \\
& $\bigcirc$ & $\bigcirc$ & $\bigcirc$ & $\bigcirc$ & $10 \%$ \\
\hline
\end{tabular}

$\mathrm{CH}_{4}$ composition is indexed on the left (blocks of four rows), $\mathrm{H}_{2}$ on the right (one value per row), and $\mathrm{N}_{2}$ by each column. Composition combinations that are considered are shown by filled (blue) circles, and those not considered are shown by open (white) circles. Color images are available online. timescales of $\sim 100,000$ s years, which is long enough to explain the formation of deposits in Gale crater (Grotzinger et al., 2015) and agrees with the timescale estimated by some valley network formation models if a high discharge frequency is assumed (Rosenberg et al., 2015). We caution the reader that the abundance of $\mathrm{N}_{2}$ in early Mars' atmosphere remains poorly constrained, and in the Discussion section we outline future steps that may be taken to improve this understanding. Note that isotopic fractionation of $\mathrm{N}_{2}$ implies a greater abundance of $\mathrm{N}_{2}$ in the early atmosphere, but few constraints have been made regarding the abundance of $\mathrm{N}_{2}$ in the early Mars atmosphere.

We investigate the production of $\mathrm{HCN}$ and nitrogen oxides in a phase space of potential early Mars climates. In Section 2, we compute lightning-induced fluxes of $\mathrm{HCN}$ and $\mathrm{NO}$ at early Mars. In Section 3, we compute $\mathrm{N}$ and $\mathrm{N}\left({ }^{2} \mathrm{D}\right)$ flux profiles that SEP events may have yielded at early Mars. In Section 4, we input these fluxes into a photochemistry and transport model to examine precipitation rates of nitrogen oxide. In Section 5, oceanic concentrations are derived considering loss through hydrolysis and photoreduction, and astrobiological relevance is investigated. In Section 6, we estimate nitrate precipitation to the surface. In Section 7, we discuss future work, and in Section 8 we summarize conclusions.

\section{Photochemistry Due to Lightning at Early Mars}

Although lightning has not been observed in the presentday Mars to date, extraterrestrial lightning associated with water clouds has been observed at Jupiter and Saturn, and lightning attributed to sulfuric acid clouds has been observed at Venus. A warm early Mars climate likely held more water in its atmosphere, supporting the assumption that lightning may have been active. Lightning is sufficiently energetic to split the triple bond of $\mathrm{N}_{2}$, thereby transforming $\mathrm{N}_{2}$ into a form that can be metabolized by most organisms. In this study, we calculate a theoretical lightning flash rate in Section 2.1, which is used in Section 2.2 to compute the associated production flux of $\mathrm{NO}$ and $\mathrm{HCN}$ in the lower atmosphere.

\subsection{Parametrizing the lightning flash rate on early Mars}

We adopt the parametrization for the lightning flash rate, $F$, from the study of Romps et al. (2014):

$$
F=\frac{\eta}{E} \cdot C A P E \cdot P
$$

where $\eta$ is a dimensionless parameter that describes the efficiency of lightning discharge energy, $E$ is the energy released per flash, $P$ is the precipitation rate per unit area, and $C A P E$ is the convective available potential energy. CAPE quantifies the convective instability of the atmosphere by measuring the maximum kinetic energy that an ascending air parcel can gain during convection. Larger CAPE gives rise to higher ascending velocity in a convective zone. Although Romps et al. (2014) did not propose a specific charging mechanism, they identified a correlation between higher updraft speeds and higher flash rates. We adopt the coefficient value, $\eta / E$, from the study of Romps 
et al. (2014) of $1.3 \times 10^{-11} / \mathrm{J}$. The parametrization of $C A P E \cdot P$ describes the maximum change in kinetic energy that water droplets in an ascending parcel of air may undergo. Note that we presently lack a thorough analysis of lightning on the scale of comparative planetology; we acknowledge this parametrization was originally derived over a localized region in the context of only terrestrial data (Romps et al., 2014). We discuss these assumptions in Section 6.1.

We use the three-dimensional (3D) general circulation model (GCM) results of Wordsworth et al. (2015) to inform $P$ and CAPE. Wordsworth et al. (2015) applied the Laboratorie de Meterologie Dynamique GCM in a transient warm wet climate, which was likely applicable on transient timescales (see Supplementary Appendix SA3). The horizontal resolution of the GCM is $3.75^{\circ}$ in latitude by $5.625^{\circ}$ in longitude, corresponding to a grid dimension of $220 \mathrm{~km}$ by $330 \mathrm{~km}$ at the equator and $220 \mathrm{~km}$ by $165 \mathrm{~km}$ at $60^{\circ}$ latitude. In a 1 bar $\mathrm{CO}_{2}$ atmosphere, the $\mathrm{H}_{2} \mathrm{O}$ mixing ratio was governed by the moist convection scheme and a gray gas absorber was used to alter the broadband IR opacity to warm the surface temperature to $\sim 300 \mathrm{~K}$. Surface topography $2.54 \mathrm{~km}$ below the geoid was considered to comprise a potential transient northern ocean (Wordsworth et al., 2015; di Achille and Hynek 2010).

We compute CAPE based on the GCM-simulated atmosphere of early Mars. We note that the concept of CAPE has been applied extensively extraterrestrially, including to the present-day Mars atmosphere (e.g., Colaprete et al., 2003; Hu et al., 2012). Physically, CAPE is determined by the abundance of moisture at the surface and the vertical profile of atmospheric temperature. In our calculation, for each grid point at each timestep in the course of the GCM simulation, an arbitrary air parcel is lifted from the surface, as defined by the initial properties of surface temperature, pressure, and specific humidity. As the air parcel ascends, the evolution of its temperature follows the dry adiabatic lapse rate $\left[\Gamma_{d}=\frac{g}{c_{p}}\right.$, where $g$ is the gravitational acceleration and $c_{p}$ is the specific heat capacity of $\mathrm{CO}_{2}$, assumed constant at $744 \mathrm{~J} /(\mathrm{kg} \cdot \mathrm{K})$ ] before saturation. After saturation is reached, the temperature profile follows the moist adiabatic lapse rate. We assume a clean atmosphere free of ice nuclei, requiring that nucleation can only happen homogeneously. Note that heterogeneous nucleation, allowing the phase transition from water vapor to water ice, would release more latent heat than homogeneous nucleation, further warming up the air parcel, and making CAPE larger. Accordingly, the condensate is assumed to be liquid water if the parcel temperature is above $-38^{\circ} \mathrm{C}$; it is assumed to be water ice if the parcel temperature is below this temperature threshold, which is the highest temperature at which homogeneous nucleation takes place. This assumption provides a lower bound of the estimated CAPE.

We derive a global mean value of $\sim 5179 \mathrm{~J} / \mathrm{kg}$, which is approximately one order of magnitude larger than typical values for the terrestrial atmosphere (Romps et al., 2014) and more than two orders of magnitude greater than that on the present-day Mars during polar night (Hu et al., 2012). Analytical terrestrial estimations demonstrate that CAPE increases in direct response to higher surface temperatures (Romps et al., 2016), and the $\sim 30 \mathrm{~K}$ warmer surface temperature of this GCM $(313 \mathrm{~K})$ compared with the terrestrial global mean temperature is a likely contributor to the larger global mean CAPE. CAPE is generally larger over the northern ocean than surface topography (by a factor of $\sim 2$ ), consistent with the terrestrial trends identified in the study of Romps et al. (2016).

The precipitation rates exhibit significant temporal variability but are on average larger by factors of $\sim 10$ and $\sim 5$ at the northern and southern poles, respectively, in comparison with the mid-to-low latitude regions $\left(<\left|60^{\circ}\right|\right)$.

The global mean flash rate is considered in the later calculations in this article, and we derive a value of $\sim 5.2 \times 10^{-17}$ flash $/\left(\mathrm{cm}^{2} \mathrm{~s}^{1}\right.$ ) (for details regarding this derivation please refer to Supplementary Appendix SA4), which is comparable with the present-day terrestrial rate and early Earth rate (as determined by the Generic LMDZ 3D global climate model; Wong et al., 2017). The derived lightning flash rate also exhibits large temporal variability due to the effect of the precipitation rate. The annual mean flash rate is demonstrated in Fig. 1, with larger values over the poles (explained by high precipitation rates) and more frequent mid-latitude $\left(\sim 30-50^{\circ}\right)$ flashes in the north due to the larger CAPE over the northern oceans.
FIG. 1. Annual mean lightning flash rate (log-scale, flash/[cm $/ \mathrm{c}])$ in a warm wet early Mars climate, assuming a global northern ocean for topography at an altitude of $-2.54 \mathrm{~km}$. Despite significant temporal variability (not shown here), we show the annual mean here since we seek to model the average early Mars environment in this study. This figure has been interpolated from the $64 \times 49$ grid of the GCM presented by Wordsworth et al. (2015). GCM, general circulation model. Color images are available online.

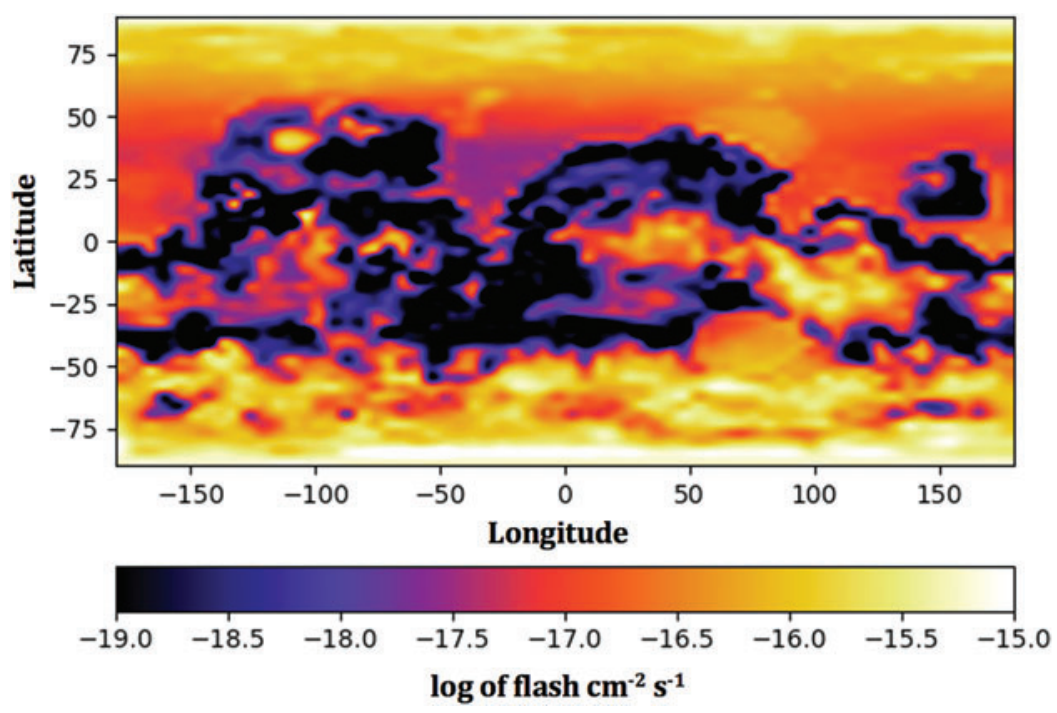




\section{2. $\mathrm{N}_{2}$ fixation through lightning}

Lightning is known to have profound local effects on atmospheric chemistry. During a lightning flash, the currentcarrying channel is heated to $3 \times 10^{4} \mathrm{~K}$, and $\mathrm{UV}$ radiative photodissociation produces radicals and complex chemistry in the vicinity of the channel. The shock wave associated with thermal expansion of the gas yields overpressures that drive the shock outward, heating surrounding gas to several thousand kelvin. At these temperatures, the atmospheric constituents are broken into radicals that recombine to form molecules stable at temperatures of several thousand kelvin, such as NOx and HCN for early Mars. The gas cools at $\sim 10^{6} \mathrm{~K} / \mathrm{s}$, and the cool atmospheric temperature quenches the gas composition out of equilibrium, but the compositions remain nearly frozen in since the reactions involved in driving the atmosphere back to equilibrium are kinetically inhibited (e.g., Desch et al., 2002 and references therein).

We calculate the NO and $\mathrm{HCN}$ mixing ratios from local thermodynamic equilibrium in the presence of lightning (approximated as $2000 \mathrm{~K}$ ) using the chemical equilibrium and applications program (McBride and Gordon, 1996). In the potential early climates considered, we find that lightning yields fluxes of $\mathrm{NO}$ and $\mathrm{HCN}$ of $\sim 10^{9}$ molecules/ $\left(\mathrm{cm}^{2} \cdot \mathrm{s}\right)$ and $\sim 10^{3}$ molecules $/\left(\mathrm{cm}^{2} \cdot \mathrm{s}\right)$ (as shown in Fig. 2). The former is comparable with the fluxes of NO on early Earth estimated by Wong et al. (2017) and Kasting et al. (1985), and may have profound astrobiological implications, which we investigate further in Section 4 when considering precipitation rates.

The NO flux is found to decrease when the abundances of reduced species are increased, whereas the $\mathrm{HCN}$ flux is found to increase due to the more reduced state, as shown in Fig. 2. Notice that neither flux varies by orders of magnitude; these are small variations that would likely not significantly affect the habitability of early Mars in the greater scheme of current uncertainties.

\section{Dissociation of $\mathrm{N}_{2}$ by SEP Events}

We use the simulation platform Geant4 (e.g., Agostinelli et $a l ., 2003)$ to approximate the response of the martian atmosphere to a coronal mass ejection (CME) and the associated SEP events. The planetary surface is represented by a uniform nonmagnetized sphere with radius $3400 \mathrm{~km}$ composed of only iron for simplicity with an STP density of $7.9 \mathrm{~g} / \mathrm{cm}^{3}$. The atmosphere is represented by a grid of 66 altitude layers extending to $110 \mathrm{~km}$ composed of pure $\mathrm{CO}_{2}$. Below $60 \mathrm{~km}$, the atmospheric temperature and eddy diffusivity (Kzz) profiles are informed by the GCM output. At higher altitudes, the temperature profile is assumed isothermal and the Kzz profile is calculated following the methods of Ackerman and Marley (2001). These profiles are also used to inform the photochemical model that follows in Section 5, and they are shown in Fig. 4. We subject the Mars atmosphere to an isotropic distribution of particles with energies ranging from $10 \mathrm{MeV}$ to $10 \mathrm{GeV}$. The energy for each particle was assigned randomly, with an algorithm designed to create a logarithmically uniform distribution. Particles are sourced from a sphere enclosing both Mars and its atmosphere; we ran two simulations with spheres of different radii, 3250 and $5280 \mathrm{~km}$, to validate that the result was independent of the arbitrary value selected. We record the initial energy of each particle and the resulting energy is deposited at each altitude layer. We binned the data by initial energy in logarithmic increments of 0.025 (40 bins per order of magnitude) for 120 bins ranging from $10 \mathrm{MeV}$ to $10 \mathrm{GeV}$, and we obtain the average deposit on a $120 \times 66$ grid over energy and altitude. We calculated the energy deposit geometric factor matrix (units of $\mathrm{MeV} \mathrm{cc^{2 }}$ ster) by multiplying this energy deposit matrix by $4 \pi 2 r^{2}$ ( $r$ is the radius of the spherical particle source). We multiplied this with the flux distribution to obtain a total energy deposit rate $(\mathrm{MeV} / \mathrm{sec})$ at each altitude. For our simulated event, we used the differential flux from the October 29, 2003, CME event as displayed in Fig. 5 from the study of Mewaldt et al. (2012). The data from the figure were extrapolated out to $6 \mathrm{GeV}$, assuming the linear $\log -\log$ relation shown in the figure, and we assume zero flux for energies $>6 \mathrm{GeV}$. The differential flux was converted to an actual flux and run through our atmospheric response matrix to obtain the energy deposit at each altitude. This describes the theoretical response of the martian atmosphere to the October 29, 2003, event.

The frequency of CMEs from the young Sun and other active stars has been estimated from their association with solar/stellar flares. SOHO/LASCO and STEREO observations show strong association of energetic and fast $(>1000 \mathrm{~km} / \mathrm{s})$ CMEs with powerful solar flares. Empirical

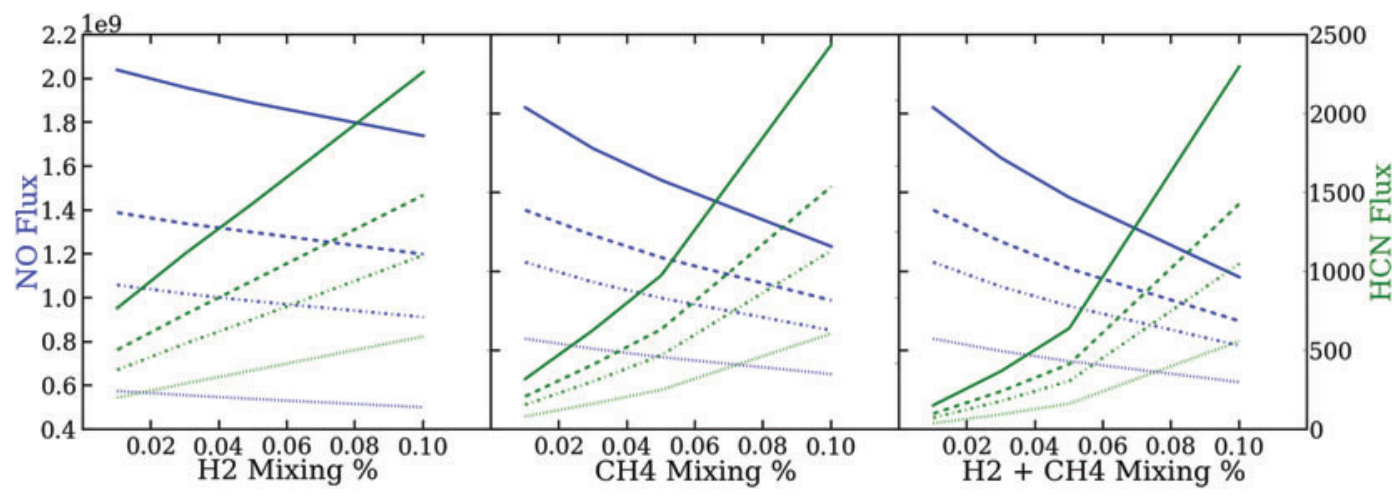

FIG. 2. Lightning-induced fluxes of $\mathrm{NO}$ (blue) and $\mathrm{HCN}$ (green) [molecules $\left./ \mathrm{cm}^{2} \cdot \mathrm{s}\right]$ produced by lightning in a $C \mathrm{O}_{2}$ background atmosphere with varied amounts of $\mathrm{N}_{2}$ (1\% dotted; $3 \%$ dot-dash; $5 \%$ dash; $10 \%$ solid), $\mathrm{H}_{2}$ (1-10\% $x$ axis of A + $\mathrm{C})$, and $\mathrm{CH}_{4}(1-10 \% x$ axis of $\mathrm{B}+\mathrm{C})$. In panels (a) and (b), $\mathrm{CH}_{4}$ and $\mathrm{H}_{2}$ (respectively) are fixed at $1 \%$. Although the molecular fluxes respond to atmospheric composition, all cases vary by less than one order of magnitude. Color images are available online. 


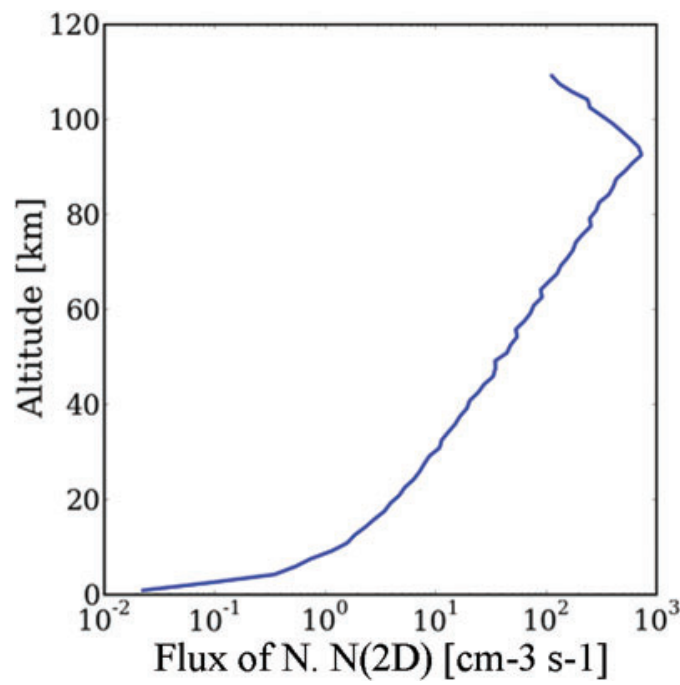

FIG. 3. $\mathrm{N}$ and $\mathrm{N}\left({ }^{2} \mathrm{D}\right)$ production rates $\left(\right.$ atoms $/ \mathrm{cm}^{3} \cdot \mathrm{s}$ ) that result from SEP events as a function of altitude, for an atmospheric composition of $10 \% \mathrm{~N}_{2}$. SEP, solar energetic particle. Color images are available online.

correlations for present solar events allow CME occurrence frequencies to be estimated from Kepler observations of the frequency of stellar superflare events at active and young $\mathrm{K}-$ $\mathrm{G}$ type main sequence stars. Lingam et al. (2018) analyzed this correlation to determine that early Mars may have experienced a few CMEs per day. In this study, we assume, on average, early Mars experienced one event per terrestrial day, each with a duration of 1 terrestrial day.

We compared the energy deposition rate at each altitude layer with the ionization rates of $\mathrm{CO}_{2}$, the dominant atmospheric constituent, and $\mathrm{N}_{2}$. We assume a 50:50 branching ratio for the products of $\mathrm{N}_{2}$ dissociation to yield $\mathrm{N}$ and $\mathrm{N}\left({ }^{2} \mathrm{D}\right)$ to derive profiles of $\mathrm{N}$ and $\mathrm{N}\left({ }^{2} \mathrm{D}\right)$ production rates induced by SEP events, as shown in Fig. 3 .

\section{Photochemical Production and Precipitation of HNOx and HCN}

To calculate the equilibrium concentration and rain out of HNOx and HCN, we adapt KINETICS, the Caltech/JPL chemical transport model (e.g., Allen et al., 1981), to the early Mars environment. Other versions of this model have been validated across numerous planetary bodies, such as Jupiter (e.g., Moses et al., 2005), Titan (e.g., Li et al., 2014), and Pluto (see, e.g., Wong et al., 2015), and a similar model was considered for the early Earth in Wong et al. (2017).

The lightning-induced fluxes for $\mathrm{NO}$ and $\mathrm{HCN}$ are injected to the lowest atmospheric level, which extends from 0 to $1.4 \mathrm{~km}$. The $\mathrm{N}$ and $\mathrm{N}\left({ }^{2} \mathrm{D}\right)$ fluxes resulting from SEP events are input as fixed altitude-dependent profiles.

We consider the chemistry of 50 species linked by 495 reactions on an altitude grid with $1-2 \mathrm{~km}$ spacing, having updated the chemical network to include all 118 reactions considered by Airapetian (2016), which examined terrestrial $\mathrm{N}_{2}$ fixation. The model calculates the chemical production and loss rates at each altitude as well as the diffusive flux between each altitude grid by solving the one-dimensional continuity equation. We consider a solar spectrum from $\sim 4.4 \mathrm{Ga}$ (Claire et al., 2012). For a complete list of chemical reactions and rates, model boundary conditions, and details regarding these equations, we refer the reader to Supplementary Appendices SA1 and SA2, respectively.

Below $60 \mathrm{~km}$, the atmospheric temperature and $K_{z z}$ profiles are informed by the GCM output. At higher altitudes, the temperature profile is assumed isothermal and the $K_{z z}$ profile is calculated following the methods of Ackerman and Marley (2001). The water vapor concentration is fixed to the saturation vapor pressure. Homogeneous nucleation of water condensation is assumed; please refer to Supplementary Appendix SA2. These profiles are shown in Fig. 4.

Our model calculates and outputs chemical abundances for each species at every level. The vertical profiles of photochemically derived $\mathrm{NO}, \mathrm{NO}_{2}, \mathrm{~N}_{2} \mathrm{O}, \mathrm{HNO}, \mathrm{HNO}_{3}$, and $\mathrm{HCN}$ in atmospheric compositions of $10 \% \mathrm{~N}_{2}, 1 \% \mathrm{CH}_{4}$, and $\mathrm{H}_{2}$, and $10 \% \mathrm{~N}_{2}, 10 \% \mathrm{CH}_{4}$, and $\mathrm{H}_{2}$ are shown in Fig. 5.

The resulting precipitation column rates of $\mathrm{HNO}$, $\mathrm{HNO}_{2}, \mathrm{HNO}_{3}, \mathrm{HO}_{2} \mathrm{NO}_{2}$, and $\mathrm{HCN}$ are found to be $\sim 10^{8}, 10^{2}, 10^{6}, 10^{3}$, and $10^{5}$ molecules $/\left(\mathrm{cm}^{2} \cdot \mathrm{s}\right)$, respectively. These fluxes also respond to variations in the abundances of $\mathrm{H}_{2}$ and $\mathrm{CH}_{4}$, as shown in Fig. 6. These responses are discussed hereunder, and the photochemical pathways governing such behavior are shown in Fig. 6 .

The precipitation rates of $\mathrm{HNO}$ appear to increase as $\mathrm{H}_{2}$ and $\mathrm{N}_{2}$ are added to the initial atmospheric abundance. The dominant formation pathway for $\mathrm{HNO}$, summarized in Fig. 7a, is through NO reacting with $\mathrm{HCO}$, and the latter is a result of $\mathrm{H}+\mathrm{CO}$. By this process, greater initial abundances of $\mathrm{H}_{2}$ enhance $\mathrm{HCO}$ concentrations, increasing the production rate of HNO. Likewise, greater initial $\mathrm{N}_{2}$ abundances directly correspond to increased lightning-induced NO fluxes (as shown in Fig. 2), and, therefore, also increase the HNO production rate.
FIG. 4. (a) Temperature (K), (b) pressure (mbar), (c) eddy diffusion coefficient $\left(\mathrm{cm}^{2} /\right.$ $\mathrm{s}$ ), and (d) water vapor concentration profiles $\left(\mathrm{cm}^{-3}\right)$ of our model atmosphere. The inversion feature in the $K_{z z}$ profile corresponds to the tropopause, as defined by the temperature profile. Color images are available online.

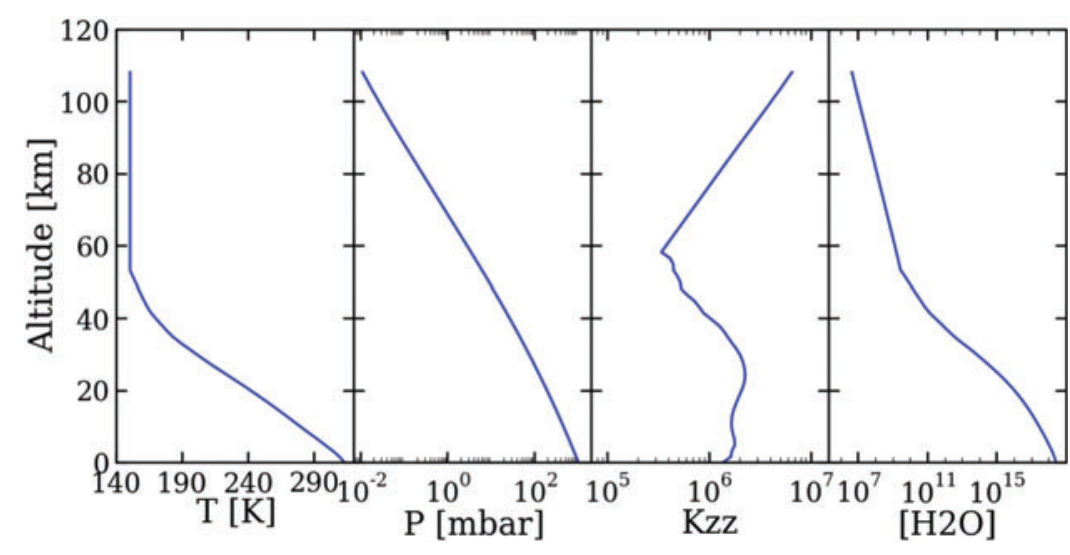




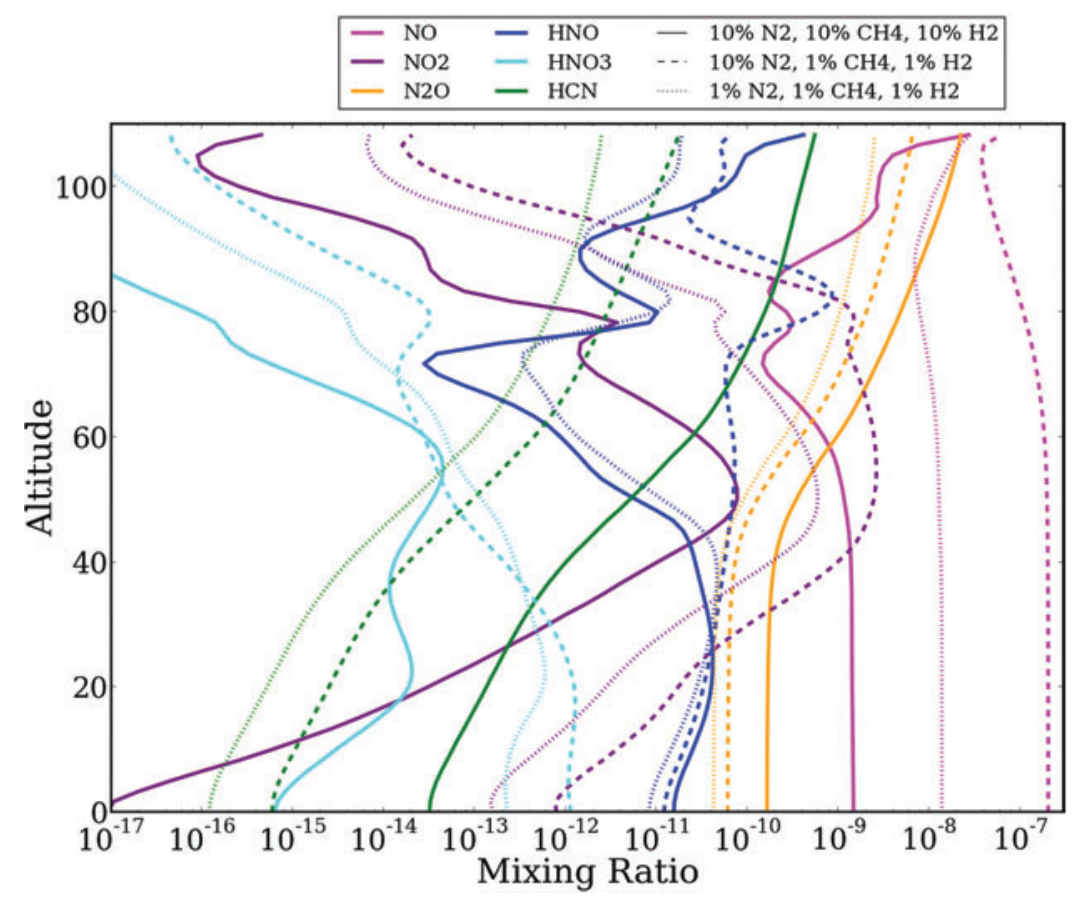

FIG. 5. Mixing ratio profiles of NO (pink), $\mathrm{NO}_{2}$ (purple), $\mathrm{N}_{2} \mathrm{O}$ (yellow), $\mathrm{HNO}$ (blue), $\mathrm{HNO}_{3}$ (cyan), and $\mathrm{HCN}$ (green) in two atmospheric compositions: $10 \% \mathrm{~N}_{2}, 10 \% \mathrm{CH}_{4}$, and $10 \% \mathrm{H}_{2}$ (dashed), and $10 \% \mathrm{~N}_{2}, 1 \% \mathrm{CH}_{4}$, and $1 \% \mathrm{H}_{2}$ (solid). Color images are available online.
$\mathrm{HNO}_{3}$ is dominantly formed through $\mathrm{NO}$ reacting with $\mathrm{HO}_{2}$, and, therefore, displays similar trends in $\mathrm{N}_{2}$ abundances. However, production of $\mathrm{HNO}_{3}$ decreases as the initial abundance of reduced gases is increased. Atmospheres with high abundances of reduced gases yield less $\mathrm{O}_{2}$, which limits $\mathrm{HO}_{2}$ (produced through $\mathrm{HCO}+\mathrm{O}_{2}$ ) and hence the formation of $\mathrm{HNO}_{3}$. We note an additional formation mechanism through $\mathrm{N}_{2} \mathrm{O}_{5}$ reacting on atmospheric ice particles; this formation mechanism dominantly occurs at night, although this can only be done in a future model that includes diurnal variation.

$\mathrm{HNO}_{2}$ and $\mathrm{HO}_{2} \mathrm{NO}_{2}$ are both formed through $\mathrm{NO}_{2}$ reacting with $\mathrm{HO}_{2}$, as shown in Fig. 7a. From Fig. 6, it is apparent that the production of both decreases in the presence of reduced gases, although the magnitude of this behavior depends on the presence of $\mathrm{N}_{2}$. $\mathrm{HO}_{2}$ again behaves as a limiting reactant in the presence of high reduced gas abundances, as in the formation of $\mathrm{HNO}_{3}$. But an important
$\mathrm{N}_{2}$ dependence is that $\mathrm{HCO}$ may form either $\mathrm{HNO}$ (in the high $\mathrm{N}_{2}$ regime) or $\mathrm{HO}_{2}$ by reacting with $\mathrm{O}_{2}$. Hence in high $\mathrm{N}_{2}$ atmospheres, $\mathrm{NO}$ is readily abundant, and $\mathrm{HCO}$ is lost to $\mathrm{HNO}$ rain out, making $\mathrm{HO}_{2}$ further limited. Hence, the abundance of $\mathrm{NO}$ affects the slope at which the reduced gas abundance decreases $\mathrm{HO}_{2}$ production and thereby the production rate of $\mathrm{HNO}_{2}$ and $\mathrm{HO}_{2} \mathrm{NO}_{2}$.

$\mathrm{HCN}$ increases by approximately one order of magnitude within the $\mathrm{N}_{2}$ range considered. HCN is formed dominantly through $\mathrm{H}_{2} \mathrm{CN}$, which is created from atomic $\mathrm{N}$ reacting with the methyl radical. $\mathrm{CH}_{3}$ is a result of $\mathrm{N}\left({ }^{2} \mathrm{D}\right)$ reacting with $\mathrm{CH}_{4}$. (Recall that both $\mathrm{N}$ and $\mathrm{N}\left({ }^{2} \mathrm{D}\right)$ are products of $\mathrm{N}_{2}$ dissociation through solar events.) This mechanism is summarized in Fig. 7b. The production rate of $\mathrm{HCN}$, therefore, depends on the concentrations of both $\mathrm{N}$ and $\mathrm{N}\left({ }^{2} \mathrm{D}\right)$, yielding an increased dependence on initial $\mathrm{N}_{2}$ abundance. The inclusion of SEP events results in a factor of $\sim 2$ increase in $\mathrm{HCN}$ production.

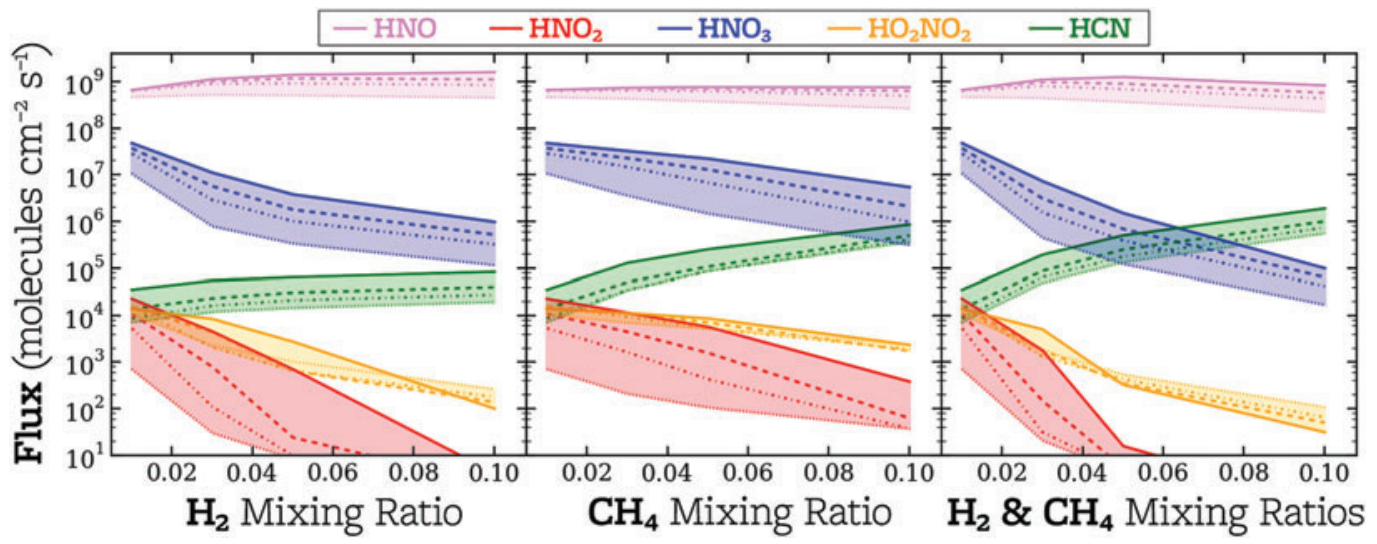

FIG. 6. Precipitation rates (fluxes) of $\mathrm{HNO}, \mathrm{HNO}_{2}, \mathrm{HNO}_{3}$, and $\mathrm{HCN}\left(\right.$ molecules $/ \mathrm{cm}^{2} \cdot \mathrm{s}$ ) (shown in pink, red, blue, and green, respectively) in atmospheres with varying mixing ratios of $\mathrm{H}_{2}$ (a), $\mathrm{CH}_{4}$ (b), and $\mathrm{H}_{2}+\mathrm{CH}_{4}$ (c). In panels (a) and (b), $\mathrm{CH}_{4}$ and $\mathrm{H}_{2}$ (respectively) are fixed at $1 \%$. In all panels, $\mathrm{N}_{2}$ is varied as the line style: $1 \%$ (dots), $3 \%$ (dot-dash), $5 \%$ (dashes), and $10 \%$ (solid line). One bar atmosphere is considered with a background composition of $\mathrm{CO}_{2}$. Color images are available online. 


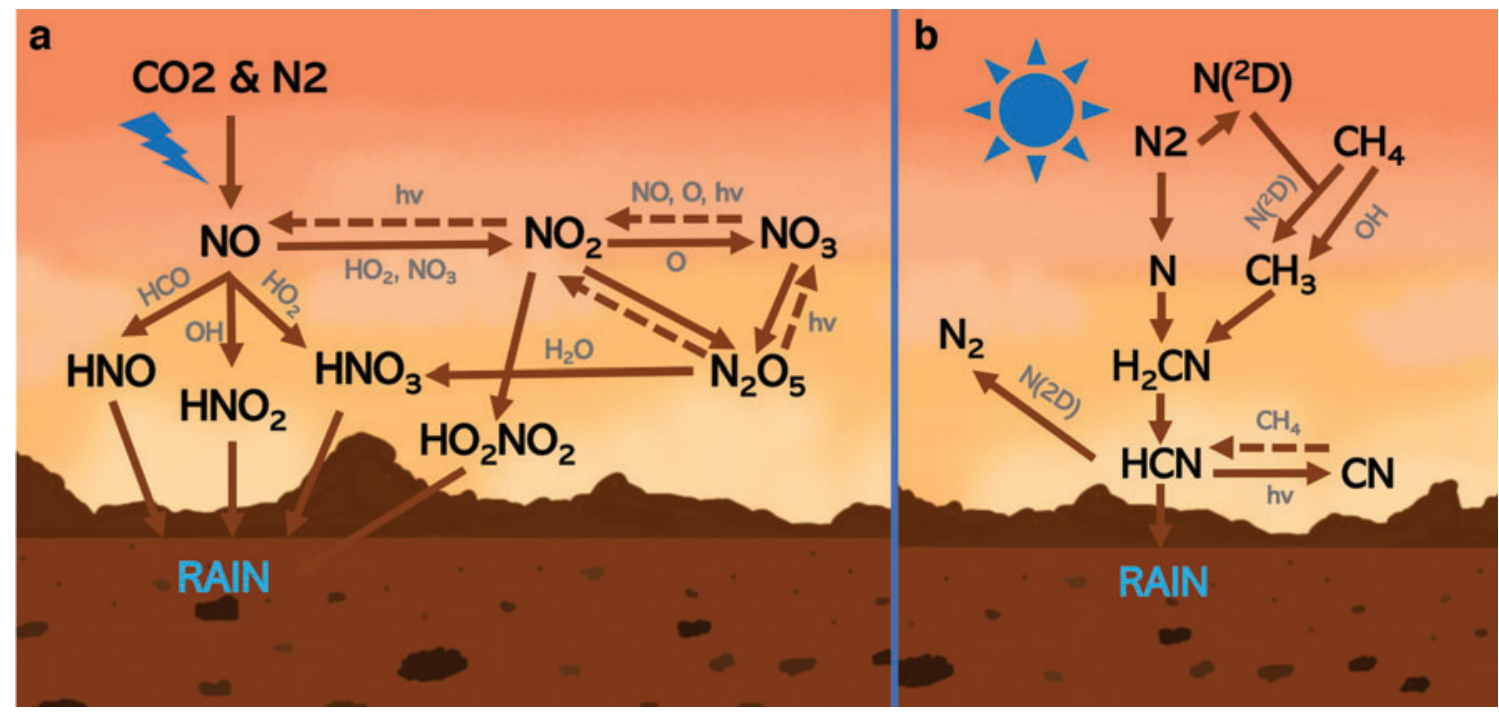

FIG. 7. Photochemical pathways describing (a) the production of HNOx and (b) the production and loss of HCN. HNOx is produced mainly by oxidizing lightning-induced $\mathrm{NO}$, and $\mathrm{HCN}$ is produced mainly through radicals, including $\mathrm{N}$ and $\mathrm{CH}_{3}$, that result from SEP events. Color images are available online.

\section{Oceanic Concentrations and Astrobiological Implications}

To assess the possibility of whether nitrate and nitrite may have acted as high-potential electron acceptors, we solve for the equilibrium concentration of nitrate in a putative global northern ocean. The putative northern ocean is motivated by a shoreline of deltaic deposits north of the dichotomy boundary (di Achille and Hynek, 2010). We consider photoreduction (Ranjan et al., 2019) and hydrolysis (Miyakawa et al., 2002) as dominant loss mechanisms of nitrate and cyanide, respectively; we compare this nitrate loss with the assumption of hydrothermal vent circulation dominating nitrate loss (e.g., Wong et al., 2017).

After raining out, HNO is of great interest due to the relatively high rain-out rates computed. It has been suggested that through the following aqueous reactions, HNO will likely produce nitrate and nitrite (Summers and Khare, 2007):

$$
\begin{gathered}
\mathrm{HNO} \rightarrow \mathrm{H}^{+}+\mathrm{NO}^{-} \\
\mathrm{NO}^{-}+\mathrm{NO} \rightarrow \mathrm{N}_{2} \mathrm{O}_{2}^{-} \\
\mathrm{N}_{2} \mathrm{O}_{2}^{-}+\mathrm{NO} \rightarrow \mathrm{N}_{3} \mathrm{O}_{3}^{-} \\
\mathrm{N}_{x} \mathrm{O}_{x}^{-} \rightarrow \mathrm{NO}_{3}^{-}+\mathrm{NO}_{2}^{-}+\mathrm{N}_{2} \mathrm{O} .
\end{gathered}
$$

$\mathrm{HNO}_{2}$ and $\mathrm{HNO}_{3}$ will dissociate into $\mathrm{H}^{+}$and $\mathrm{NO}_{2}{ }^{-}$or $\mathrm{NO}_{3}{ }^{-}$respectively, and $\mathrm{HO}_{2} \mathrm{NO}_{2}$ will deoxygenate rapidly to produce nitrite and $\mathrm{O}_{2}$. $\mathrm{Hu}$ et al. (2019) analyzed the kinetic rates of aqueous-phase chemistry and determined that the mentioned mechanism should be inefficient in Archean Earth's ocean. In this study, we adopt the former mechanism of Summers and Khare (2007) for early Mars and discuss its impact on our results in Section 6.

HCN can be destroyed through hydrolysis, and the first product would be formamide. The stability of formamide has not been exhaustively studied, but it is a potential solvent for prebiotic reactions it can be concentrated and is itself a prebiotic reagent. However, the consideration of this specie is beyond the scope of our study. We fit the laboratory hydrolysis rates from the study of Miyakawa et al. (2002) to an Arrhenius equation to find a hydrolysis kinetic rate of $2.265 \times 10^{-12}$ molecules $/\left(\mathrm{cm}^{2} \cdot \mathrm{s}\right)$, which corresponds to a temperature of $273 \mathrm{~K}$.

Intense heating (to $\sim 700 \mathrm{~K}$ ) as ocean water circulates through acidic hydrothermal vents would have acted as a significant loss process. Heterogeneous distributions of zinc and gypsum veins suggest aqueous alteration through impact-generated hydrothermal vents in the terrains of early Mars (e.g., Squyres et al., 2012). At these high temperatures, iron minerals within the crusts would have reduced nitrate and nitrite to $\mathrm{N}_{2}$. Additional reduction through cooler serpentinization-driven alkaline springs may have likely yielded ammonia, adding alkaline vents to the loss as well (Gordon et al., 2013). To consider hydrothermal vent circulation alone, we derive resulting oceanic concentrations, following the methods of Wong et al. (2017), as

$$
C=\frac{f_{\text {atm }} A_{M} \tau_{H T V}}{V_{\text {ocean }}},
$$

where $f_{a t m}$ is the HNOx flux from the atmosphere (molecules $\left./\left(\mathrm{cm}^{2} \cdot \mathrm{s}\right)\right), A_{M}$ is the area of Mars, $\tau_{H T V}$ is the timescale for cycling through high-temperature vents, and $V_{\text {ocean }}$ is the volume of the northern ocean, which we approximate in our study as the full northern hemisphere. Notice that $\tau_{H T V}=V_{\text {ocean }} / F_{H T V}$, where $F_{H T V}$ is the mass flux of water through high-temperature hydrothermal vents for which we adopt the current terrestrial water mass flux from hightemperature vents, $7.2 \times 10^{12} \mathrm{~kg} /$ year. The equilibrium concentration may then be expressed as

$$
C=\frac{f_{a t m} A_{M}}{F_{H T V}} .
$$

With hydrothermal vent circulation acting as the only source of nitrate destruction in early surface waters, concentrations of $\sim 0.001-0.01 \mathrm{M}$ nitrate are found, which is 
slightly lower than the concentration expected at early Earth of $0.024 \mathrm{M}$ under this same assumption (Wong et al., 2017).

However, the concentration expressed in Eq. (5) would overestimate the concentration of nitrate, which undergoes further destruction in surface waters. We, therefore, also incorporate photodestruction to compute a concentration of nitrate in surface waters. Photolysis by UV radiation reduces nitrate to nitrite and nitrite to gaseous $\mathrm{NO}$, which may directly escape to the atmosphere or become reduced to $\mathrm{N}_{2} \mathrm{O}$ before escaping (see, e.g., Ranjan et al., 2019):

$$
\begin{gathered}
\mathrm{NO}_{3}^{-}+h v \rightarrow \mathrm{NO}_{2}^{-}+\frac{1}{2} \mathrm{O}_{2} \\
\mathrm{NO}_{2}^{-}+\mathrm{H}_{2} \mathrm{O}+h v \rightarrow \mathrm{NO}+\mathrm{OH}+\mathrm{OH}^{-} .
\end{gathered}
$$

These processes have been measured in present-day terrestrial oceans to have median rate constants of $\mathrm{k}_{\mathrm{NO} 3-\mathrm{hv}}=2.3 \times 10^{-8} / \mathrm{s}$ and $\mathrm{k}_{\mathrm{NO} 2-\mathrm{hv}}=1.2 \times 10^{-6} / \mathrm{s}$ for nitrate and nitrite, respectively (Mack and Bolton, 1999). Although $\mathrm{OH}$ may oxidize nitrite to nitrate, nitrite is lost with 20 $100 \%$ efficiency in the presence of bicarbonate, $\mathrm{Br}^{-}$, and other $\mathrm{OH}$ scavengers (e.g., Zafiriuo and True, 1979). We assume surface water temperatures of $273 \mathrm{~K}$, and we note that the photolysis rates increase by a factor of up to $\sim 4$ had we assumed a temperature up to $50 \mathrm{~K}$ greater (Ranjan et al., 2019). Furthermore, we acknowledge that the incident solar flux at the early Mars surface would differ from that at present-day Earth, attributed to both the change in solar spectrum over time and the different atmospheric optical depths due to the two differing compositions. To account for this, we use a KINETICS output adapted to present-day Earth (Li et al., 2017) to compare the two incident fluxes between 200 and $400 \mathrm{~nm}$ (the dominant wavelengths that contribute to photoreduction). Early Mars, accounting for the faint young Sun and attenuation through an atmosphere of different optical depth, is found to experience a flux that is $27.2 \times$ greater than present-day Earth, and we linearly scale the rates above. Hence, we consider the following rate constants for our calculation: $\mathrm{k}_{\mathrm{NO} 3-\mathrm{hv}}=6.26 \times 10^{-7} / \mathrm{s}$ and $\mathrm{k}_{\mathrm{NO} 2-\mathrm{hv}}=3.26 \times 10^{-5} / \mathrm{s}$.
We find nitrate and cyanide concentration values of $\sim 0.1-2 \mathrm{nM}$ and $\sim 0.01-2 \mathrm{mM}$ (respectively) in a putative northern ocean at early Mars. Note that despite a much less efficient rain out of HCN compared with HNOx, the slower loss mechanism (or, the lack of photodestruction) generally allows a greater concentration of cyanide in the surface waters than nitrate. For both species, the variation attributed to the different atmospheric compositions considered is linearly comparable with the rain-out fluxes shown in Fig. 8, and is again due to the photochemical processes described in Section 4.

Recall from Section 1 that $\mathrm{NO}_{3}{ }^{-}$and $\mathrm{HCN}$ may have been astrobiologically relevant in concentrations of $1 \mu \mathrm{mol}$ and $0.01 \mathrm{~mol}$, respectively. Both concentrations derived in our model are significantly more dilute. It is likely that secondary concentrating processes of $\mathrm{HCN}$ would be required for the production of adenine or amino acids, as expected by previous terrestrial study (e.g., Holm and Neubeck, 2009). We suggest that future work, particularly laboratory experiments, could investigate the relevance of more dilute nitrate concentrations in scenarios thought to be important to the onset of metabolism. Future studies may also draw comparisons with the nitrate deposits identified previously by the MSL (Stern et al., 2015; Sutter et al., 2017).

\section{Estimating Nitrate Precipitation}

We next consider what these results imply about expected concentrations of nitrate in the martian regolith. We assume salts would precipitate to the surface from the acids after evaporation of surface waters, likely during the Amazonian eon, and we make several assumptions to calculate the concentration of salts that would have deposited. The concentration of acids can be expressed in terms of column mass of nitrate per unit surface area, spread over the northern hemisphere in the putative northern ocean assumed throughout this article. We assume the nitrates would have deposited in the first $2 \mathrm{~m}$ of the Mars soil, which is the mean of three e-folding depths of the $\sim 0.51-0.85 \mathrm{~m} \mathrm{1/e}$ mixing depths that small postNoachian impactors would have churned the soil (Zent, 1998). We assume a soil density of $1 \mathrm{~g} / \mathrm{cc}$ (Moore and Jakosky, 1989).

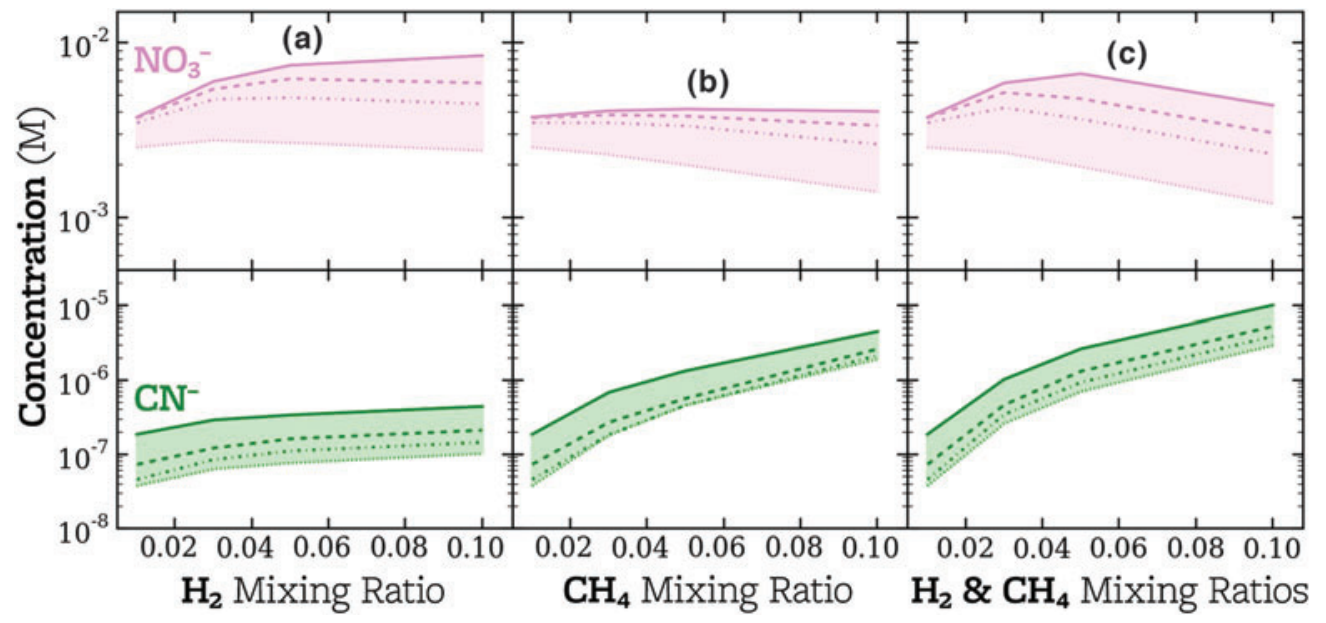

FIG. 8. Concentrations of nitrate (top) and cyanide (bottom) assuming hydrothermal vent circulation as the only loss mechanism for both species (as in Wong et al., 2017). The following are varied from $1 \%$ to $10 \%$ : (a) $\mathrm{H}_{2}$, (b) $\mathrm{CH}_{4}$, and (c) both $\mathrm{H}_{2}$ and $\mathrm{CH}_{4}$. In panels (a) and (b), $\mathrm{H}_{2}$ and $\mathrm{CH}_{4}$ (respectively) are fixed at $1 \%$. In all panels, $\mathrm{N}_{2}$ is varied as the line style: $1 \%$ (dots), $3 \%$ (dot-dash), $5 \%$ (dashes), and 10\% (solid line). One bar atmosphere of background $\mathrm{CO}_{2}$ is considered. Color images are available online. 


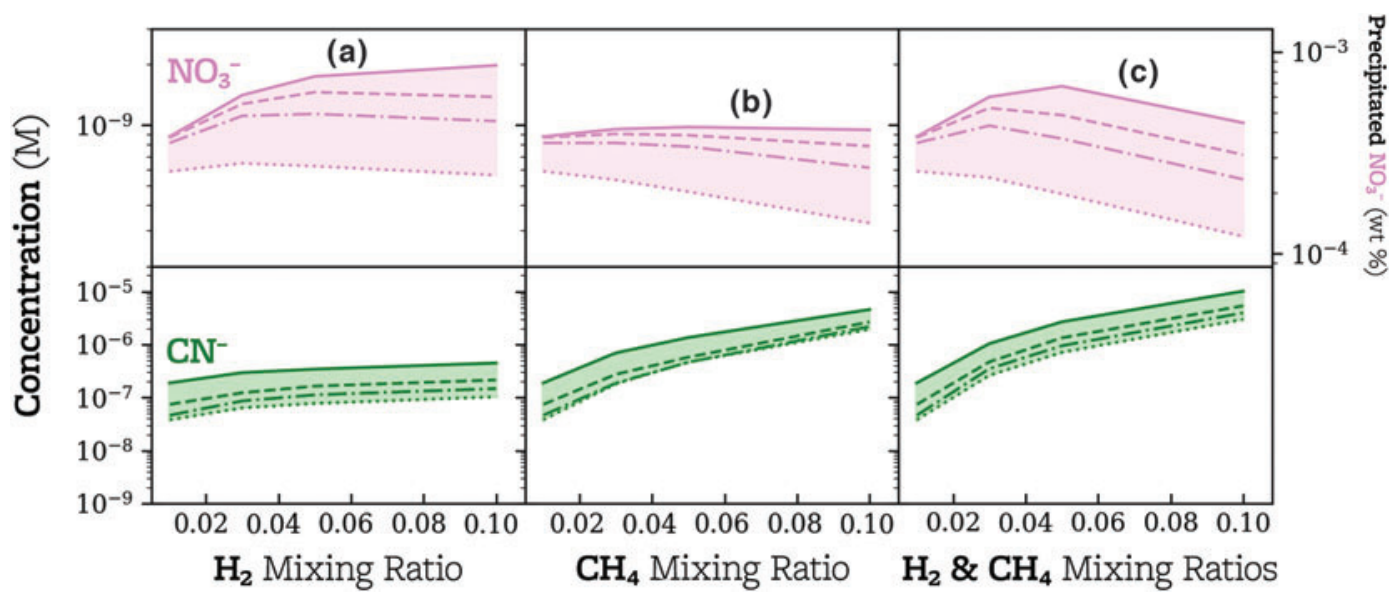

FIG. 9. Concentrations of $\mathrm{CN}^{-}$(green) and $\mathrm{NO}_{3}^{-}$(pink) in oceans are shown ( $y$ axis) and are compared across varied atmospheric compositions ( $x$ axis, linestyle). The following are varied from $1 \%$ to $10 \%$ : (a) $\mathrm{H}_{2}$, (b) $\mathrm{CH}_{4}$, and (c) both $\mathrm{H}_{2}$ and $\mathrm{CH}_{4}$. In panels (a) and (b), $\mathrm{H}_{2}$ and $\mathrm{CH}_{4}$ (respectively) are fixed at $1 \%$. In all panels, $\mathrm{N}_{2}$ is varied as the line style: $1 \%$ (dots), $3 \%$ (dot-dash), $5 \%$ (dashes), and $10 \%$ (solid line). One bar atmosphere of background $\mathrm{CO}_{2}$ is considered. Color images are available online.

We compute the weight percent of nitrate precipitates that may have formed in each climate composition considered, and we find values between $\sim 1$ and $8 \times 10^{-4}$ wt $\%$. The nitrate precipitation concentrations demonstrate a similar response to climate composition as the formerly presented aqueous concentrations, since the response of both is determined by the response of the rain-out fluxes to the atmospheric composition.

Sutter et al. (2017) measured present-day surface nitrate abundances of $\sim 0.002$ to $0.05 \mathrm{wt} \%$, and Stern et al. (2015) measured $\sim 70-260$ and $\sim 330-1100 \mathrm{ppm}$. The largest range of values from our model thus agrees with the lowest range measured by Stern et al. (2015), and is a factor of two from the lowest range in the study of Sutter et al. (2017). The best match is represented by an atmospheric composition rich in $\mathrm{H}_{2}$, or by a moderate ( $\sim 3 \%$ each) combination of $\mathrm{H}_{2}$ and $\mathrm{CH}_{4}$ in the atmosphere.

We compute salt precipitation directly from the equilibrium oceanic acid concentrations, but this assumption neglects the following processes. First, photoreduction of aqueous nitrates is efficient only above the photic depth, which we define to be two-thirds of the present-day terrestrial photic depth at the equator of $5 \mathrm{~m}$ (the scaling to average over latitude). Evaporation would not be instantaneous, and once water evaporates to be shallower than the photic depth, acids may be more concentrated in this near-surface layer. In this case, photoreduction would become more efficient, decreasing the amount of nitrate precipitation that would form on the surface. Second, since evaporation would not be instantaneous, assuming the entire northern hemisphere as the depositing surface area may be an overestimate. In the absence of an ocean (e.g., ponds), photodestruction would be more efficient (since they would be shallower), but the surface area of deposition would decrease. Third, in the early case of a deep ocean, nitrates may react with dissolved cations to sink and precipitate to the ocean floor. Similarly, if nitrates were involved in biological processes, the death of oceanic creatures would also result in the sinking and deposition of nitrate-bearing compounds to the ocean floor. The sinking and burial of nitrates would protect them from photoreduction, decreasing the efficiency of loss and thus increasing the concentration of surface precipitates.

\section{Discussion}

\subsection{Parametrizing lightning on global scales across comparative planetology}

Romps et al. (2014) derived Eq. (1) as an approximation to estimate lightning over the United States (a localized region), and deviations within an order of magnitude are known to exist over the continents versus oceans (Romps et al., 2016). We acknowledge that this parametrization lacks mechanistic underpinnings, whereas the true flash rate may depend on the atmospheric scale height, atmospheric constituents, the presence/absence of a mixed-phase region in the deep convection, and the gravitational constant through its impact on particle fall speeds. Some of these parameters (scale height, constituents, and surface gravity) are included in the GCM and may be captured by the dependence of F on CAPE and P. This parametrization has been used in previous studies regarding early Earth (Wong et al., 2017). We solve for CAPE and P directly, and we assume $\mathrm{E}$ is comparable with that of present-day Earth noting that the electrostatic breakdown field is thought to not vary strongly with the local composition of the gas (Helling et al., 2013). However, the constant $\eta$ in Eq. (1) is likely not a best fit on global scales at other worlds, which makes the scaling relation in this parametrization likely valid only to an order of magnitude; $\eta$ is not physically motivated but is a best fit parameter (Romps et al., 2014) and, therefore, the uncertainty in applying this relation to other worlds is large (David Romps, private communication). Since no constraints can be made to date, we accept the parametrization and suggest future work investigate parametrizing lightning globally on other worlds.

In calculating the lightning flash rate, we obtain the precipitation rate and derive CAPE from GCM outputs from the study of Wordsworth et al. (2015), which considered a 1 bar $\mathrm{CO}_{2}$ atmosphere with a gray gas absorber to explain a fairly high surface temperature of $300 \mathrm{~K}$. A gray gas absorber cannot be considered in kinetics models, but the reducing 
gases we consider $\left(1-10 \% \mathrm{H}_{2}\right.$ and $\mathrm{CH}_{4}$, which are excluded from the GCM) have a similar warming effect due to collision-induced absorption (Wordsworth et al., 2017). We also consider $1-10 \%$ abundances of $\mathrm{N}_{2}$, though no $\mathrm{N}_{2}$ was considered in the GCM. Despite the exclusion of trace gases from the GCM, since the bulk composition $\left(\mathrm{CO}_{2}\right)$ is the same in both the GCM and our models, we expect that our model set up is not far from self-consistent, and uncertainties from the small difference are likely small.

It is necessary to note that results of CAPE calculation depend on the convection scheme in the GCM, and the LMD GCM in this study only employs a simple convection scheme as described in Manabe and Strickler (1964), in which convective adjustments are applied where the radiation-determined temperature profiles are convectively unstable. Therefore, we interpret the CAPE results in this study as an order-of-magnitude estimate. Future studies with more realistic GCM simulations that use mesoscale models such as PlanetWRF (Richardson et al., 2007) need to be conducted to provide a more accurate estimate of CAPE on early Mars and validate the conclusions in this study.

\subsection{Fixed $\mathrm{N}_{2}$ in surface waters}

In addition to surface delivery through rain out, $\mathrm{Hu}$ et al. (2019) calculated nitrate deposition by considering aqueous chemistry in the ocean and atmosphere-ocean equilibrium. This study derives a flux of nitrate deposition comparable with that of Wong et al. (2017), but demonstrates that oceanic feedback to the gaseous deposition will remove HNO before the formation of nitrates. Hence, our oceanic concentrations are likely upper limits for the derived nitrate flux into surface waters. We intend for future study to incorporate the feedback mechanism of $\mathrm{Hu}$ et al. (2019) to determine its impact on early Mars' nitrate formation.

Nitrate reduction by reactions with iron (e.g., Buchwald et al., 2016) has been identified as an additional loss mechanism. The neglection of this loss is motivated by present-day terrestrial measurements, in which dissolved ferrous iron is able to circulate thousands of kilometers from hydrothermal vent sites, in the presence of abundant nitrate and nitrite (Fitzsimmons et al., 2014). Furthermore, Ranjan et al. (2019) examined the relevance of this loss in the context of hydrothermal vent circulation and photoreduction; the reaction rates for reduction by iron are poorly constrained and yield uncertainties of greater than eight orders of magnitude, and the mechanism would only change our result should it be faster than photoreduction. We suggest that future laboratory work constrains these reaction rates to improve uncertainties.

Cyanide in surface waters would likely also react with iron to form ferrocyanic salts. Toner and Catling (2019) investigated the fate of varied fixed partial pressures of atmospheric $\mathrm{HCN}$ gas (ignoring rain out to aqueously deliver cyanide). They found that ferrocyanic salts would form from gaseous HCN reacting with surface iron, and subsequent thermal decomposition of the salts would release cyanide to the waters in equilibrium. We deem an aqueous chemistry model is beyond the scope of this study, but we predict that aqueously delivered cyanide to early Mars surface waters would lead to an equilibrium composition of both aqueous cyanide and ferrocyanic salts.
Throughout this study, we assume a putative northern ocean at early Mars. Although some evidence has been explored (e.g., di Achille and Hynek, 2010), the presence of an ancient ocean is still highly uncertain and debated (e.g., Palumbo et al., 2018). Surface lakes and/or ponds are a plausible scenario (e.g., Grotzinger et al., 2015); however, investigating fixed $\mathrm{N}_{2}$ concentrations in smaller bodies of water would require some estimate of the fraction of early Mars' surface area covered by this water (which presently is poorly constrained). HCN hydrolysis is not sensitive to depth, and would approximately be homogeneous throughout any body of water (although the rate of destruction would respond to water $\mathrm{pH}$, Miyakawa et al., 2002). Hence, the concentration of HCN in small bodies of water would inversely scale with the total volume of surface water across the planet. Photoreduction of NOx is sensitive to depth, and primarily only occurs above a photic depth of $\sim 100 \mathrm{~s} \mathrm{~cm}$. Hence, destruction of nitrates would be more rapid in small ponds, yielding a more dilute concentration (e.g., Ranjan et al., 2019). However, for both species, the catchment area feeding into a lake/pond would introduce significant uncertainty, as would weather, mineralogy, and proximity to a volcano. Hence, it is difficult to model such systems when using global models such as ours.

\section{Conclusions}

The $\mathrm{N}_{2}$ cycle remains one of the long-standing questions regarding early Mars habitability and has strong ties to profound astrobiological implications. We estimated $\mathrm{NO}$ and HCN lightning-induced fluxes of $\sim 10^{9}$ and $\sim 10^{3} /\left(\mathrm{cm}^{2} \cdot \mathrm{s}\right)$, respectively, by computing thermochemical equilibrium with chemical equilibrium with applications in regions of lighting, parametrized following the methods from the study of Romps et al. (2014). We computed $\mathrm{N}$ and $\mathrm{N}\left({ }^{2} \mathrm{D}\right)$ flux profiles (peaking nearly at $10^{3} /\left[\mathrm{cm}^{3} \cdot \mathrm{s}\right]$ ) yielded by SEP events with a Geant4 simulation platform. Using KINETICS (the Caltech/ JPL model that considers photochemistry and transport), we derived precipitation rates of HNOx and $\mathrm{HCN}$ (of $\sim 10^{9}$ and $\sim 10^{5}$, respectively). In a putative northern ocean at early Mars, assuming loss through hydrothermal vent circulation we find concentrations of $\sim 3-20 \mathrm{mM}$ nitrate and $\sim 0.01-$ $2 \mathrm{mM}$ cyanide, and assuming nitrate loss through photodestruction, we find nitrate concentrations of $\sim 0.1-2 \mathrm{nM}$. We suggest future work to investigate the astrobiological relevance of these concentrations. After the evaporation of surface waters, these acids may have precipitated out as salts that would correspond to precipitates of $\sim 1-8 \times 10^{-4}$ wt $\%$.

\section{Author Disclosure Statement}

No competing financial interests exist.

\section{Acknowledgments}

We thank Pin Chen, Armin Kleinboehl, Robin Wordsworth, David Romps, Stuart Bartlett, and Rob Lillis for useful discussions.

\section{Funding Information}

D.A. was supported by NASA's FINESST program under Proposal Number 80NSSC19K1548. M.L.W. was supported by NASA's Virtual Planetary Laboratory under NASA Astrobiology Institute Cooperative Agreement Number NNA13AA93A and Grant Number 80NSSC18K0829. C.D. 
was supported by NASA's Habitable Worlds program under Proposal Number 80NSSC18K0288. The research was carried out at the Jet Propulsion Laboratory, California Institute of Technology, under a contract with the National Aeronautics and Space Administration (80NM0018D0004). This research was initiated under and partially supported by a NASA Habitable Worlds grant (\#NNN130466T, later changed to \#80NM0018F0612) to Pl R.H. and Co-I Y.L.Y.

\section{Supplementary Material}

Supplementary Appendix SA1

Supplementary Appendix SA2

Supplementary Appendix SA3

Supplementary Appendix SA4

\section{References}

Ackerman AS, Marley MS (2001) Precipitating condensation clouds in substellar atmospheres. Astrophys $J$ 556:2.

Airapetian VS (2016) The environment of the young earth in the perspective of a young sun. Living Around Active Stars, Proceedings IAU Symposium No. 328, doi:10.1017/ S1743921317004288.

Allen M, Yung YL, Waters JW (1981) Vertical transport and photochemistry in the terrestrial mesosphere and lower thermosphere (50-120f km). J Geophys Res 86:3617-3627.

Baker VR (2006) Geomorphological evidence for water on mars. Elements 2:139-143.

Baranov YI, Lafferty WJ, Fraser GT (2004) Infrared spectrum of the continuum and dimer absorption in the vicinity of the $\mathrm{O} 2$ vibrational fundamental in $\mathrm{O} 2 / \mathrm{CO} 2$ mixtures. $\mathrm{J} \mathrm{Mol}$ Spectrosc 228:432-440.

Bibring J-P, Langevin Y, Mustard JF, et al. (2006) Global mineralogical and aqueous mars history derived from OMEGA/mars express data. Science 312:400-404.

Bigeleisen J (1949) The relative reaction velocities of isotopic molecules. J Chem Phys 17:675-678.

Buchwald C, Grabb K, Hansel CM, et al. (2016) Constraining the role of iron in environmental nitrogen transformations: dual stable isotope systematics of abiotic no 2-Reduction by Fe (II) and its production of N2O. Geochim Cosmoch Acta 186:1-12.

Desch SJ, Borucki W, Russell CT, et al. (2002) Progress in planetary lightning. Rep Progr Phys 65:955:997.

Di Achille G., Hynek B (2010) Ancient ocean on mars supported by global distribution of deltas and valleys. Nat Geosci 3:459-463.

Dong C, Huang Z, Lingham M, et al. (2018) The dehydration of water worlds via atmospheric losses. Astrophy J Lett 847:1.

Ducluzeau AL, van Lis R, Duval S, et al. (2009) Was nitric oxide the first deep electron sink? Trends Bioochem Sci 34:9-15.

Fitzsimmons JN, Boyle EA, Jenkins WJ (2014) Distal transport of dissolved hydrothermal iron in the deep South Pacific Ocean. Proc Natl Acad Sci U S A 111:16654-16661.

Forget F, Pierrehumbert R (1997) Warming early Mars with carbon dioxide clouds that scatter infrared radiation. Science 278:1273-1276.

Fripiat JJ, Poncelet G, van Assche AT, et al. (1972) Zeolite as catalysts for the synthesis of amino acids and purines. Clays Clay Miner 20:331-339.

Gannes LZ, Martinez Del Rio C, Koch P (1998) Natural abundance variations in stable isotopes and their potential uses in animal physiological ecology. Comput Biochem Physiol 119A:725-737.

Gordon AD, Smirnov A, Shumlas SL, et al. (2013) Reduction of nitrite and nitrate on nano-dimensioned FeS. Orig Life Evol Biosph 43:305-322.
Gough DO (1981) Solar interior structure and luminosity variations. Solar Phys 74:21-34.

Grotzinger JP, Gupta S, Malin MC, et al. (2015) Deposition, exhumation, and paleoclimate of an ancient lake deposit, gale crater, mars. Science 350:aac7575.

Gruszka M, Borysow A (1997). Roto-translational collisioninduced absorption of $\mathrm{CO} 2$ for the atmosphere of Venus at frequencies from 0 to $250 \mathrm{~cm}^{-1}$, at temperatures from 200 to 800K Icarus 129:172-177.

Halevy I, Head JW (2014) Episodic warming of early Mars by punctuated volcanism. Nat Geosci 7:865-868.

Hashimoto GL, Abe Y, Sugita S (2007) The chemical composition of the early terrestrial atmosphere: formation of a reducing atmosphere from CI-like material. J Geophys Res 112: E05010.

Helz GR, Erickson BE, Vorlicek TP (2014) Stabilities of thiomolybdate complexes of iron; implications for retention of essential trace elements $(\mathrm{Fe}, \mathrm{Cu}, \mathrm{Mo})$ in sulfidic waters. Metallomics 6:1131-1140.

Hoering $\mathrm{T}$ (1956) The isotopic composition of the ammonia and the nitrate ion in rain. Geochim Cosmochim 12:97-102.

Holm N, Neubeck A (2009) Reduction of nitrogen compounds in oceanic basement and its implications for $\mathrm{HCN}$ formation and abiotic organic synthesis. Geochem Trans 10:9.

Hu R, Kass D, Ehlmann B, et al. (2015) Tracing the fate of carbon and the atmospheric evolution of Mars. Nat Commun 6:10003.

Huber C, Wachterschauser G (1997) Activated acetic acid by carbon fixation on $(\mathrm{Fe}, \mathrm{Ni}) \mathrm{S}$ under primordial conditions. Science 276:245-247.

Ikgersoe E (1953) Nonradiogenic isotopes in geology. Bull Geolog Soc Am 64:301.

Jakosky BM, Brain D, Chafffin M, et al. (2018) Loss of the Martian atmosphere to space: present-day loss rates determined from MAVEN observations and integrated loss through time. Icarus 315:146-157.

Kasting JF (1988) Runaway and moist greenhouse atmospheres and the evolution of Earth and Venus. Icarus 74:472-494.

Kasting JF (1991). CO2 condensation and the climate of early Mars. Icarus 94:1-13.

Kite E, Williams J-P, Lucas A, et al. (2014) Low paleopressure of the Martian atmosphere estimated from the size distribution of ancient craters. Nat Geosci 7:335-339.

Li C, Zhang X, Kammer JA, et al. (2014) A non-monotonic eddy diffusivity profile of Titan's atmosphere revealed by Cassini observations. Planet Space Sci 104:48-58.

Li K-F, Zhang Q, Wang S, et al. (2017) Resolving modelobservation discrepancy in the mesospheric and stratospheric HOx chemistry. Earth Space Sci 4:607-624.

Lingam M, Dong C, Fang X, et al. (2018) The propitious role of solar energetic particles in the origin of life. ApJ 853:10.

Mack J, Bolton JR (1999) Photochemistry of nitrite and nitrate in aqueous solution: a review. J Photochem Photobiol A Chem 128:1-13.

Macko SA, Fogel-Estep ML, Engel MH, et al. (1986) Kinetic fractionation of nitrogen isotopes during amino acid transamination. Geochim Cosmochim Acta 50:2143-2146.

Manabe S, Strickler RF (1964) Thermal equilibrium of the atmosphere with a convective adjustment. J Atmosph Sci 21:361-385.

Mancinelli RL. McKay CP (1988) The evolution of nitrogen cycling. Orig Life Evol Biosph 18:311-325.

McBride B., Gordon S (1996) Computer program for calculation of complex chemical equilibrium compositions and applications. NASA Reference Publication, 1311.

McElroy MB, Yung YL, Nier AO (1976) Isotopic composition of nitrogen-implications for past history of mars atmosphere. Science 194:70-72. 
McEwen AS, Dundas CM, Mattson SS, et al. (2013) Recurring slope lineae in equatorial regions of mars. Nat Geosci 7:53-58.

Mewaldt RA, Looper MD, Cohen CMS, et al. (2012) Energy spectra, composition, and other properties of ground-level events during solar cycle 23. Space Sci Rev 171:97-120.

Milliken RE, Grotzinger JP, Thomson BJ (2010) Paleoclimate of mars as captured by the stratigraphic record in gale crater. Geophys Res Lett 37:L04201.

Minagawa M, Wada E (1984) Stepwise enrichment of 15N along food chains: further evidence and the relation between $\mathrm{d} 15 \mathrm{~N}$ and animal age. Geochim Cosmochim Acta 48:1135-1140.

Moses JI, Fouchet T, Bezard B, et al. (2005) Photochemistry and diffusion in Jupiter's stratosphere: constraints from ISO observations and comparisons with other giant planets. $J$ Geophys Res 110:E8.

Nier AO, McElroy MB, Yung YL (1976) Isotopic composition of the martian atmosphere. Science 194:68-70.

Nitschke W. Russell MJ (2013) Beating the acetyl coenzyme A-pathway to the origin of life. Philos Trans $R$ Soc Lond B Biol Sci 368:20120258.

Oro J (1960) Synthesis of adenine from hydrogen cyanide. Biochem Biophys Res Commun 2:407-412.

Oro J (1961) Mechanisms of synthesis of adenine from hydrogen cyanide under possible primitive Earth conditions. Nature 191:1193-1194.

Pearce BK. D., Ayers PW, Pudritz RE (2019) A consistent reduced network for $\mathrm{HCN}$ chemistry in early Earth and Titan atmospheres: quantum calculations of reaction rate coefficients. J Phys Chem A 123:1861-1873.

Ranjan S, Todd Z, Rimmer P, et al. (2019) Nitrogen oxide concentrations in natural waters on early Earth. Geochem Geophys Geosyst 20:2021-2039.

Richardson MI, Toigo AD, Newman CE (2007) PlanetWRF: a general purpose, local to global numerical model for planetary atmospheric and climate dynamics. J Geophys Res Planets 112:E09001.

Ritson D, Sutherland JD (2012) Prebiotic synthesis of simple sugars by photoredox systems chemistry. Nat Chem 4:895.

Ritson DJ, Sutherland JD (2013) Synthesis of aldehydic ribonucleotide and amino acid precursors by photoredox chemistry. Angewandte Chem Int Ed 52:5845-5847.

Romps DM, Seeley JT, Vollaro D, et al. (2014) Projected increase in lightning strikes in the United States due to global warming. Science 346:851-854.

Romps DM, Charn AB, Holzworth RH, et al. (2016) CAPE times P explains lightning over land but not the land-ocean contrast. Geophys Res Lett 45:12623-12630.

Russell MJ, Martin W (2004) The rocky roots of the acetyl-CoA pathway. Trends Biochem Sci 29:358-363.

Schaefer L, Fegley B (2007) Outgassing of ordinary chondritic material and some of its implications for the chemistry of asteroids, planets, and satellites. Icarus 186:462-483.

Schoepp-Cothenet B, van Lis R, Philippot P, et al. (2012) The ineluctable requirement for the trans-iron elements molybdenum and/or tungsten in the origin of life. Sci Rep 2:1-5.

Schuman U, Huntrieser H (2007) The global lightning induced nitrogen oxides source. Atmos Chem Phys Discuss 7:26232818.

Shibuya T, Russell MJ, Takai K (2016) Free energy distribution and hydrothermal mineral precipitation in Hadean submarine alkaline vent systems: importance of iron redox reactions under anoxic conditions. Geochim Cosmochim Acta 175:1-19.

Squyres S, Arvidson R, Bell III, J, et al. (2012) Ancient impact and aqueous processes at endeavour crater, mars. Science 336:570-575.
Stern JC, Sutter B, Freissinet C, et al. (2015) Evidence for indigenous nitrogen in sedimentary and aeolian deposits from the Curiosity rover investigations at Gale crater, Mars. Proc Natl Acad Sci USA 112:4245-4250.

Summers DP, Khare B (2007) Nitrogen fixation on early Mars and other terrestrial planets: experimental demonstration of abiotic fixation reactions to nitrite and nitrate. Astrobiology 7 : 333-341.

Sutherland JD (2017) Opinion: studies on the origin of life - the end of the beginning. Nat Rev Chem 1:1-7.

Sutter B, McAdams AC, Mahaffy P, et al. (2017) Evolved gas analyses of sedimentary rocks and eolian sediment in Gale Crater, Mars: results of the Curiosity Rover's sample analysis at Mars instrument from Yellowknife Bay to the Namib Dune. J Geophys Res Planets 122:2574-2609.

Urata RA, Toon OB (2013) Simulations of the Martian hydrologic cycle with a general circulation model: implications for the ancient Martian climate. Icarus 226:229-250.

Wong MH, Atreya SK, Mahaffy PN, et al. (2013) Isotopes of nitrogen on Mars: atmospheric measurements by Curiosity's mass spectrometer. Geophys Res Lett 40:6033-6037.

Wong ML, Yung YL, Gladstone GR (2015) Pluto's implications for a snowball titan. Icarus 246:192-196.

Wong ML, Charnay BD, Gao P, et al. (2017) Nitrogen oxides in early Earth's atmosphere as electron acceptors for life's emergence. Astrobiology 17:975-983.

Wordsworth R, Forget F, Millour E, et al. (2013) Global modelling of the early Martian climate under a denser $\mathrm{CO} 2$ atmosphere: water cycle and ice evolution. Icarus 222:1-19.

Wordsworth R, Kerber L, Pierrehumbert, et al. (2015) Comparison of "warm and wet" and "cold and icy" scenarios for early Mars in a 3-D climate model. J Geophys Res Planets 120:1201-1219.

Wordsworth R, Kalugina Y, Lokshtanov S, et al. (2017) Transient reducing greenhouse warming on early Mars. Geophys Res Lett 44:665-671.

Yung YL, DeMore WB (1999) Photochemistry of Planetary Atmospheres. New York: Oxford University Press.

Zanden M, Rasmussen J (2001) Variation in d15N and d13C trophic fractionation: implications for aquatic food web studies. Limnol Oceanogr 46:2061-2066.

Address correspondence to: Danica Adams Department of Geological and Planetary Sciences California Institute of Technology 1200 E California Boulevard Pasadena, CA 91125-0002 USA

E-mail: djadams@caltech.edu

Submitted 7 April 2020 Accepted 26 April 2021

$\begin{aligned} & \text { Abbreviations Used } \\ & 3 \mathrm{D}=\text { three-dimensional } \\ & \mathrm{CME}=\text { coronal mass ejection } \\ & \mathrm{GCM}=\text { general circulation model } \\ & \mathrm{MSL}=\text { Mars Science Laboratory } \\ & \mathrm{NO}_{2}{ }^{-}=\text {nitrite } \\ & \mathrm{NO}_{3}^{-}=\text {nitrate } \\ & \mathrm{SEP}=\text { solar energetic particle } \\ &\end{aligned}$

